\title{
Kinesio Taping Improves Perceptions of Pain and Function of Patients With Knee Osteoarthritis: A Randomized, Controlled Trial
}

\author{
Anna Lina Rahlf, Klaus-Michael Braumann, and Astrid Zech
}

\begin{abstract}
Context: Although increasingly used for therapeutic treatment, only limited evidence exists regarding the effects of kinesio taping on patients with knee osteoarthritis (OA). Objective: To determine the effects of kinesio taping on pain, function, gait, and neuromuscular control concerning patients with knee OA. Design: Randomized sham-controlled trial. Setting: University laboratory. Participants: A total of 141 patients (65.1 [7.0] y) with a clinical and radiographic diagnosis of knee OA. Intervention: Kinesio tape, sham tape, or no tape for 3 consecutive days. Main Outcome Measures: Self-reported pain, stiffness, and function were measured by the Western Ontario and McMaster Universities Osteoarthritis Index (WOMAC). Further tests included the Balance Error Scoring System, 10-m walk test, the maximum voluntary isometric contraction force of the quadriceps femoris, and knee active range of motion. Results: At baseline, there were no differences in all outcomes between groups except for knee flexion. Significant effects were found for WOMAC pain (tape vs sham, $P=.05$; tape vs control, $P=.047$ ), stiffness (tape vs sham, $P=.01$; tape vs control, $P \leq .001$ ), and physical function (tape vs sham, $P=.03$; tape vs control $P=.004$ ). No interactions were found for balance, muscle strength, walking speed, or active range of motion. Conclusion: Wearing kinesio tape for 3 consecutive days had beneficial effects regarding self-reported clinical outcomes of pain, joint stiffness, and function. This emphasizes that kinesio taping might be an adequate conservative treatment for the symptoms of knee OA.
\end{abstract}

Keywords: knee joint, physical activity, randomized control trial, rehabilitation

Osteoarthritis is one of the most frequent musculoskeletal disorders in older adults. ${ }^{1,2}$ The current global prevalence of knee osteoarthritis (OA) is $3.8 \%$, and women are affected more often $(4.8 \%)$ than men. ${ }^{3}$ In the past, OA was generally known as degenerative cartilage decrease. Today, $\mathrm{OA}$ is defined as a disease that involves the whole joint including cartilage, menisci, subchondral bone, synovium, capsule, ligaments, and muscles. ${ }^{1,2,4,5}$ The primary focus of nonsurgical treatment is on the reduction of main symptoms of pain and stiffness ${ }^{3}$ as well as on improvement of functional capacities. A conservative therapeutic approach for the treatment of musculoskeletal disorders that increasingly gained attention of clinicians and physiotherapists in the last years is kinesio taping. However, due to the lack of research studies, little is known regarding the influence on clinically relevant symptoms or underlying physiological changes responsible for potential effects. Consequently, the use and benefits of kinesio taping are still controversially discussed. ${ }^{6}$

The results of the few existing studies on the effects of kinesio taping in general are mostly inconsistent ${ }^{7,8}$ and produce uncertainty regarding the clinical value. Significant effects were found for pain perception and joint range of motion (ROM) in patients with acute whiplash ${ }^{9}$ and shoulder impingement ${ }^{10}$. Other studies reported tendencies for an improved proprioception ${ }^{1-17}$ and lymph flow $^{18,19}$ as well as changes in muscles tone. ${ }^{20-24}$ Regarding knee $\mathrm{OA}, 2$ recently published studies indicate beneficial effects of kinesio tape on reducing pain, improving isokinetic quadriceps torque, ${ }^{25}$ pain-free ROM, and proprioception. ${ }^{26}$ However, both

Rahlf and Zech are with the Department of Exercise Physiology, Institute of Sport Science, Friedrich-Schiller-University of Jena, Jena, Germany. Braumann is with the Department of Sports Medicine, University of Hamburg, Hamburg, Germany. Rahlf (anna.lina.rahlf@uni-jena.de) is corresponding author. studies had a small sample size, and patients underwent posttest measurements immediately after kinesio tape application. Therefore, the short-term effectiveness of the therapeutic use of kinesio taping in OA patients is still unclear.

The objective of this study was to determine the effects of kinesio tape on perceptions of pain and function as well as on ROM, strength, balance, and walking abilities. The results of this study will help to provide evidence-based recommendations regarding the use of kinesio tape for treating OA-related functional limitations.

\section{Methods}

\section{Design}

A randomized sham-controlled trial was conducted between January 2015 and October 2015 (Figure 1). Patients were randomly allocated into an intervention group, sham group, or control group. Randomization was carried out using numbered labels in concealed envelopes. The subjects had to pull an envelope from a nontransparent vessel, after the baseline measurement. Thus, the concealed allocation could be ensured. Patients in the intervention and sham groups were blinded regarding the treatment. Both groups were told to receive an effective kinesio tape for the knee joint, only with a difference in the application area. The control group was not blinded. All measurements were accomplished at the university laboratory of the Department of Exercise Physiology. The data collection was conducted by the same examiner. Due to the applied tape in the follow-up measure, it was not possible to blind the examiner regarding the study group allocation. All performed procedures were conducted according to the Declaration of Helsinki (1975) and were ethically approved by the local ethics committee at Friedrich Schiller University Jena. 


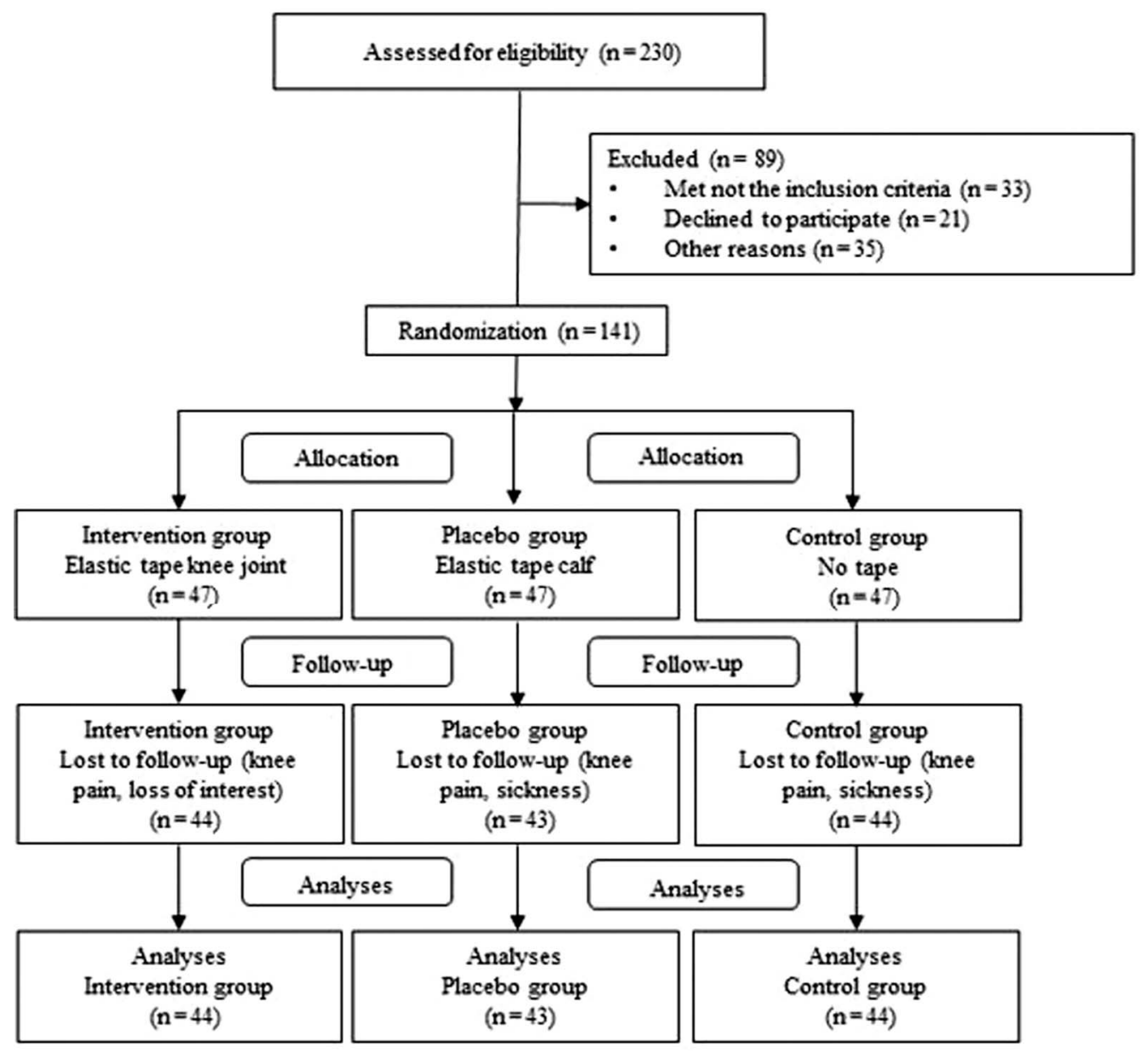

Figure 1 - CONSORT flow diagram of the study process including numbers of participants.

\section{Participants}

Patients were recruited through advertisement in newspapers and direct mailings in cooperation with local clinicians, resulting in an assessment for eligibility of 230 subjects. Patients with a clinical and radiographic diagnosis of knee OA, certified by an orthopedic surgeon, and an age of 50 years or older were considered for inclusion. There is an increasing risk for elderly people beyond 50 to get OA. ${ }^{3}$ As the clinical symptoms do not always agree with the X-ray, ${ }^{27}$ all degrees of severity of knee OA were included in this study. Exclusion criteria were acute inflammation or pain with edema, a recent or simultaneous pharmacological treatment, a surgical intervention in the past 6 months, skin diseases or irritations or another previous total or partial joint endoprosthesis. All participants received written information of the study and signed the consent after being informed.

\section{Procedures}

On the basis of previous knee OA studies, ${ }^{28-30}$ primary outcomes of pain and physical function were measured by the Western Ontario and McMaster Universities Osteoarthritis Index (WOMAC). The questionnaire included 24 questions, divided in 3 subscales: pain, stiffness, and physical function. It was answered by a validated 10 points rating scale. ${ }^{29}$ All items were answered retrospectively for the last 2 days.
Balance, walking speed, isometric quadriceps torque, and ROM were secondary outcomes. Static balance was measured by the Balance Error Scoring System (BESS). ${ }^{31,32}$ Patients stood with hands on hips and eyes closed as still as possible for 20 seconds during 6 conditions of increasing challenge: doubleleg, tandem, and single-leg stance on (1) firm and (2) foam surface. In each condition, the number of the following errors was counted: lifting hands off iliac crests, opening eyes, stepping, stumbling, falling, moving the hip more than $30^{\circ}$, lifting the forefoot or heel, and remaining out of the testing position for more than 5 seconds. ${ }^{33}$

The maximum walking speed was measured by the timed 10 -m walk test. ${ }^{34}$ To determine the maximum speed, the patients started $2 \mathrm{~m}$ before the starting line and stopped $2 \mathrm{~m}$ after the finish line. The time was only measured $10 \mathrm{~m}$ between start and finish lines.

Maximum isometric knee extension strength was assessed using an isokinetic dynamometer (Isomed 2000; D\&R Ferstl, Hemau, Germany). The subjects sat in an upright position with $90^{\circ}$ flexion in the hip joint on the chair. The pelvic and the torso were secured with straps to prevent body movements. The lateral femur condyle was used as anatomical orientation, for a precise axis of rotation of the knee joint and the dynamometer. The dynamometer lever arm was fixed $2 \mathrm{~cm}$ above the lateral malleolus. To ensure a $90^{\circ}$ flexion during the testing situation, the knee joint was 
fixed at $95^{\circ}$ to control the deformation of the shin pad. ${ }^{35}$ Gravity correction was made in a relaxed extension using integrated function of the software. Before starting the measurement, the subjects performed 2 submaximal exertions with a 2-minute break in between, in order to become familiar with the dynamometer. Each test included 3 maximum contractions $(3 \mathrm{~s}$ for each contraction) with a rest interval of 3 minutes. The peak torque of the 3 -second trial was used to determine the maximum voluntary isometric contraction (MVIC). Subsequently, the best of the 3 trials (highest contraction force) was used for data analysis. Every testing situation was supervised, and verbal encouragement was given by the same investigator.

The active ROM of knee flexion and extension was tested using a $360^{\circ}$ double-armed goniometer by the same instructor. ${ }^{36}$ Measurements were performed in supine position with the goniometer fulcrum placed on the lateral epicondyle of the femur. Knee-flexion ROM was defined as the maximum deviation from the neutral zero position. ${ }^{37}$ Subjects performed the active knee flexion independently.

All tests were conducted in a fixed order with strength test at last to avoid exhaustion while testing.

Patients who were allocated into the intervention group received a kinesio tape on the knee following the current standard of "Kinesiological Taping" by Kase et al. ${ }^{38}$ A medial and a lateral "I"-strap as well as 1 "I"-strap over the patella were applied (Figure 2A). "I"-strap means the tape is not cut into different parts; it is applied in the full width and mainly used to limit edema and pain. ${ }^{38}$ The strap across the patella was applied in individual maximum knee flexion. The base of the tape was applied at the tibial tuberosity and pulled in maximum tension over the patella, ending at the lower third of the quadriceps femoris muscle. The medial and lateral straps were applied in $45^{\circ}$ knee flexion along the collateral medial and lateral ligaments. Patients in the sham group received a tape distal to the knee without tension and without affecting the knee joint (Figure 2B). The tape was applied with straight legs, lying prostrate on a bench. The kinesio tape and sham tape were applied immediately after baseline measurements by a physiotherapist with certificate and long-term experience in elastic taping. Tapes were worn for 3 consecutive days and were removed after the last measurement at posttest. The effect was examined with still applied tape to capture the original condition during a tape period. Patients in the control group had no intervention but were given the opportunity to receive the kinesio tape after study participation.

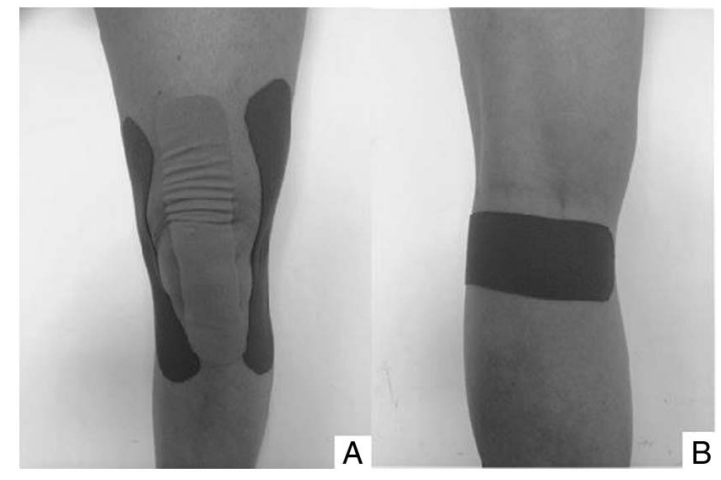

Figure 2 - (A) Kinesio tape of the intervention group and (B) Sham tape.

\section{Statistical Analyses}

The sample size calculation indicated that 98 participants were needed to get a clinical relevant effect for the WOMAC Questionnaire $(f=0.39)^{39}$ with a statistical power of $90 \%$ at an alpha level equal to .05 .

One-way analysis of variance was used to detect baseline differences between groups at baseline in demographics and primary and secondary outcomes. Intervention effects were determined using the analysis of covariance ( $95 \%$ confidence interval) including the mean difference from baseline to follow-up. Dependent variables were WOMAC pain, stiffness, and function as well as the BESS, MVIC, 10-m walk test, and ROM. Group allocation was defined as independent factor, and the age was included as covariate to recognize a possible age-related impairment of the measurements. This analysis was made because age has been shown to correlate with the diagnosis OA. The post hoc comparison of the 3 groups was made using a Bonferroni correction. All calculations were based on an intention-to-treat analysis. The statistical analysis was performed using the Statistical Package for Social Science software (version 22.0; IBM Corp, Armonk, NY).

\section{Results}

Of the 230 patients with a knee OA among whom underwent the eligibility screening, 141 joined the study and 131 completed posttests (Figure 1). The dropout rate was $7 \%$ of all participants $(n=3$ in the intervention group, $n=4$ in the sham group, and $n=3$ in controls) and appeared because of sickness, pain in the knee, or loss of interest in participating. As all reasons of dropouts were registered, it can be considered that none of the dropouts were due to the intervention.

At baseline, no differences were found between groups in demographics and anthropometric variables (Table 1). In primary and secondary outcomes, significant baseline differences between groups were found for active knee flexion $(P=.04)$ (Table 1).

Baseline to posttest changes as well as statistics are presented in Table 2. Significant intervention effects were found for the 3 WOMAC subscales (pain: $F_{2,135}=3.82, P=.02$; stiffness: $F_{2,135}=7.27, P=.001$; function: $\left.F_{2,135}=6.08, P=.003\right)$. In secondary outcomes, no significant intervention effects were found, although the greatest improvements were observed in the kinesio tape group (Table 2). Age had no significant influence on the primary outcomes (Table 2).

Post hoc analyses revealed significant group differences in the WOMAC between the tape and sham groups (pain: $P=.05$, stiffness: $P=.01$, function: $P=.03$ ) as well as the tape and the control groups (pain: $P=.047$, stiffness: $P=.001$, function: $P=.004)$. No significant differences were found between the sham and control groups (Table 3 ).

\section{Discussion}

The main finding of this study is that wearing a kinesio tape over 3 consecutive days is effective to improve the self-reported perception of pain, joint stiffness, and physical function in patients with OA compared with a sham tape or no intervention. Although this emphasizes the benefits of kinesio tape for the treatment for major symptoms of OA, the underlying mechanism responsible for these effects are still speculative. 
Table 1 Baseline Demographic Data of the Tape, Sham, and Control Groups

\begin{tabular}{|c|c|c|c|c|c|}
\hline & Tape $(n=47)$ & Sham $(n=47)$ & Control $(n=47)$ & $F_{2,140}$ & $P$ value \\
\hline Sex, male/female & $23 / 24$ & $21 / 26$ & $23 / 24$ & & .58 \\
\hline Affected side, left/right & $20 / 27$ & $17 / 30$ & $22 / 25$ & & .90 \\
\hline Age, y & $64.7(7.3)$ & $65.3(6.0)$ & $65.4(7.6)$ & 0.13 & .87 \\
\hline Height, $\mathrm{cm}$ & $172.2(8.3)$ & $169.6(8.8)$ & $170.8(8.8)$ & 0.97 & .38 \\
\hline Weight, kg & $85.0(18.4)$ & $80.0(15.7)$ & $78.3(13.4)$ & 2.25 & .11 \\
\hline WOMAC pain, points & $3.33(1.35)$ & $3.67(1.34)$ & $3.58(1.27)$ & 0.82 & .45 \\
\hline WOMAC stiffness, points & $4.06(1.88)$ & $4.30(2.03)$ & $4.11(2.02)$ & 0.19 & .80 \\
\hline WOMAC function, points & $3.44(1.51)$ & $3.76(1.78)$ & $3.50(1.30)$ & 0.57 & .57 \\
\hline BESS, error points & $21.96(7.85)$ & $22.79(10.12)$ & $20.64(7.5) 0$ & 0.75 & .47 \\
\hline MIVC, N·m & $118.06(54.30)$ & $115.27(49.42)$ & $117.66(57.40)$ & 0.04 & .96 \\
\hline $10-\mathrm{m}$ walk test, $\mathrm{s}$ & $6.07(1.25)$ & $6.07(1.78)$ & $5.81(1.31)$ & 0.50 & .61 \\
\hline Active flexion, deg & $126.81(8.56)$ & $126.06(9.11)$ & $130.0(6.17)$ & 3.22 & .04 \\
\hline Active extension, deg & $6.0(5.77)$ & $6.32(6.07)$ & $5.36(5.43)$ & 0.34 & .72 \\
\hline
\end{tabular}

Abbreviations: BESS, Balance Error Scoring System; MVIC, maximum voluntary isometric contraction; WOMAC, Western Ontario and McMaster Universities Osteoarthritis Index. Note: Data are presented as mean (SD). The analysis was made with an $\alpha$ of .05.

Table 2 ANCOVA Analysis of the Mean Difference From Baseline To Follow-Up After 3 Days

\begin{tabular}{|c|c|c|c|c|c|c|c|}
\hline & $\begin{array}{c}\text { Tape group, } \\
\text { mean (SD) }\end{array}$ & $\begin{array}{c}\text { Sham group, } \\
\text { mean (SD) }\end{array}$ & $\begin{array}{c}\text { Control group, } \\
\text { mean (SD) }\end{array}$ & $F_{d f}$ & $\begin{array}{c}\text { Group } \\
(P \text { value })\end{array}$ & $F_{d f}$ & $\begin{array}{c}\text { Age } \\
\text { ( } P \text { value) }\end{array}$ \\
\hline WOMAC pain, points & $-0.70(1.2)$ & $-0.13(1.20)$ & $-0.12(0.87)$ & $3.82_{2,135}$ & .02 & $3.09_{1,135}$ & .09 \\
\hline WOMAC stiffness, points & $-1.22(1.50)$ & $-0.30(1.54)$ & $-0.07(1.57)$ & $7.27_{2,135}$ & .001 & $2.03_{1,135}$ & .19 \\
\hline WOMAC function, points & $-0.80(1.00)$ & $-0.29(1.11)$ & $-0.14(0.70)$ & $6.08_{2,135}$ & .003 & $1.66_{1,135}$ & .26 \\
\hline BESS, error points & $-2.00(3.75)$ & $-1.57(5.59)$ & $-1.13(3.81)$ & $0.42_{2,135}$ & .59 & $3.41_{1,135}$ & .06 \\
\hline MIVC, N.m & $4.91(19.00)$ & $2.71(12.55)$ & $-0.86(19.72)$ & $1.41_{2,131}$ & .25 & $1.40_{1,131}$ & .23 \\
\hline 10-m walk test, s & $-0.29(0.45)$ & $-0.28(0.53)$ & $-0.17(0.62)$ & $0.94_{2,134}$ & .44 & $0.91_{1,134}$ & .27 \\
\hline Active flexion, deg & $0.60(4.47)$ & $-0.96(5.36)$ & $0.13(4.63)$ & $1.30_{2,135}$ & .28 & $0.03_{1,135}$ & .93 \\
\hline Active extension, deg & $0.85(4.21)$ & $1.09(3.87)$ & $0.06(3.66)$ & $1.05_{2,135}$ & .37 & $0.01_{2,135}$ & .98 \\
\hline
\end{tabular}

Abbreviations: ANCOVA, analysis of covariance; BESS, Balance Error Scoring System; MVIC, maximum voluntary isometric contraction; WOMAC, Western Ontario and McMaster Universities Osteoarthritis Index. The analysis was made with an $\alpha$ of .05 .

Table 3 Post Hoc Groupwise Comparison of Absolute Differences Between the Tape, Sham, and Control Groups

\begin{tabular}{|c|c|c|c|c|c|c|}
\hline & \multicolumn{2}{|c|}{ Tape vs sham } & \multicolumn{2}{|c|}{ Tape vs control } & \multicolumn{2}{|c|}{ Sham vs control } \\
\hline & $95 \% \mathrm{Cl}$ & $P$ value & $95 \% \mathrm{Cl}$ & $P$ value & $95 \% \mathrm{Cl}$ & $P$ value \\
\hline WOMAC pain, points & -1.14 to 0.03 & .05 & -1.17 to -0.01 & .047 & -0.62 to 0.55 & $>.99$ \\
\hline WOMAC stiffness, points & -1.74 to -0.13 & .01 & -1.97 to -0.39 & .001 & -1.04 to 0.55 & $>.99$ \\
\hline WOMAC function, points & -1.00 to -0.01 & .03 & -1.16 to -0.19 & .004 & -0.66 to 0.32 & $>.99$ \\
\hline BESS, error points & -2.99 to 1.77 & $>.99$ & -3.20 to 1.47 & $>.99$ & -2.59 to 2.08 & $>.99$ \\
\hline MVIC, N.m & -6.73 to 12.07 & $>.99$ & -2.90 to 15.76 & .29 & -5.61 to 13.13 & .99 \\
\hline 10-m walk test, s & -0.30 to 0.27 & $>.99$ & -0.42 to 0.14 & .67 & -0.41 to 0.15 & .78 \\
\hline Active flexion, deg & -0.90 to 4.22 & .35 & -2.02 to 3.02 & $>.99$ & -3.70 to 1.38 & .81 \\
\hline Active extension, deg & -2.21 to 1.66 & $>.99$ & -1.09 to 2.73 & .90 & -0.82 to 3.02 & .51 \\
\hline
\end{tabular}

Abbreviations: BESS, Balance Error Scoring System; CI, confidence interval; MVIC, maximum voluntary isometric contraction; WOMAC, Western Ontario and McMaster Universities Osteoarthritis Index. Note: The analysis was made with an $\alpha$ of 05 .

It is hypothesized that the elasticity of the tape and its application under tension leads to a mobilization of the skin during movements ${ }^{38}$ and improves blood and lymph circulation. This mechanism is believed to influence directly pain perception. ${ }^{11}$ Another frequently discussed influencing factor is the stimulation of cutaneous mechanoreceptors. ${ }^{40}$ This may change the interactions between cutaneous mechanoreceptors and proprioception and could be responsible for the decreased perception of stiffness ${ }^{41}$ in the kinesio tape group observed in our study. As knee pain considerably limits perceptions of joint function, ${ }^{42}$ the present study conclude that the improved perception of pain and stiffness may be responsible for the increased function in 
participants of the tape group. However, although these circumstances may be plausible explanations for the observed findings, to date, no evidence exists regarding the physiological effects of kinesio tape. Further research should therefore focus on the true underlying mechanism for the beneficial taping effects.

Furthermore, the clinical relevance of WOMAC changes needs to be critically discussed. According to Escobar et al, ${ }^{39}$ a minimum of clinical important difference in the WOMAC score must be located at 1.5 points. However, Angst et $\mathrm{al}^{43}$ indicated that the difference should be more than $12 \%$ of baseline measurement or $6 \%$ of the maximum value to be clinically relevant. In this case, the WOMAC changes in our study can be considered clinical relevant. Nevertheless, it should be taken into account that for other conservative treatments higher effects were shown. For example, Knoop et $\mathrm{al}^{44}$ reported an $18 \%$ change in WOMAC physical function after a knee stabilization training. Compared with our findings, one may speculate that the use of a stabilization program is more effective than kinesio taping to reduce symptoms of pain and limited function. However, whereas the effect of regular exercising takes some weeks, the kinesio tape improves pain perception immediately after application.9,10,25,26 Based on these results, a combined intervention of functional exercises with applied tape would be a useful therapy for patients with knee OA particularly in the transition period.

Regarding secondary outcomes, beneficial but not significant kinesio tape effects were found for standing balance skills. This means, the tape group was more able to improve the BESS score from baseline to follow-up compared with the sham and control groups. The BESS score in our study ranges higher than the BESS score in other studies with participants in a comparable age. ${ }^{45}$ This suggests that, beside the increased age, ${ }^{45}$ potential limitations or instabilities of the knee OA negatively influenced the balance. Other studies that have dealt with the influence of kinesio tape on balance mainly focused on ankle instability in healthy young adults and used different assessments. ${ }^{13-17}$

No changes were found for other secondary outcomes. This is partially contrary to the previously reported findings. $9,10,25,26$ Based on the study of Staehli et al, ${ }^{46}$ the MVIC of the knee extensors was determined as the parameter for possible muscular changes for patients with knee OA. The authors found high relative reliability scores (intraclass correlation coefficient: .95), ${ }^{46}$ which led to a recommendation to use this technique in the present study. This measurement is in contrast to the previous studies, where the authors preferred isokinetic measurements to detect differences in muscle strength after kinesio tape application. ${ }^{25,47-51}$ Although isometric measurement was not statistically significant in our study, the kinesio tape group showed the greatest increase of MVIC compared with the other groups. Contrary to our findings, Anandkumar et $\mathrm{al}^{25}$ reported a significantly increased isokinetic knee-extensor torque 30 minutes after the application of the tape in patients with knee OA, whereas Fu et al, ${ }^{47}$ Aytar et al, ${ }^{48}$ Lins et al, ${ }^{49}$ Vercelli et al, ${ }^{50}$ and Wong et $\mathrm{al}^{51}$ observed no significant changes. The contradictory findings between our study and the study of Anandkumar et $\mathrm{al}^{25}$ may be explained by the different use of the kinesio tape and the use of isokinetic measurement instead of isometric measurement. Although the study of Anandkumar et $\mathrm{al}^{25}$ used a tape application for the entire quadriceps femoris muscle, we included only the muscle structures close to the knee joint.

For walking speed, no significant effects were observed, although mean values improved in all groups. This implies that the significantly improved perceptions of pain, joint stiffness, and physical function had no influence on the functional walking performance. In this context, it may also be speculated whether the $10-\mathrm{m}$ walk test is suitable to detect changes in walking abilities in patients with OA. It seems also plausible that the shown WOMAC changes have been too low to induce clinically relevant changes in parameters of physical function.

Compared with the already previously mentioned optimal knee-flexion ROM with $150^{\circ}$ and extension with $0^{\circ},{ }^{37}$ the baseline measurement showed a deficit of the ROM in all groups in both directions. This indicates the typical functional impairment of OA. ${ }^{52-54}$ However, no significant effects of the kinesio tape were found for ROM of the knee. This is contrary to the study of Cho et $\mathrm{al}^{26}$ who found significant changes in the pain-free active ROM in patients with knee OA.

The strength of the study comprised an acceptable sample size in the 3 groups and a solid methodology. Due to the follow-up measurements with applied tape, the realistic tape situation could be examined. For this study, it was important to prove the tape when it is still in function and not to observe the effectiveness after removal.

However, there were limitations due to the lack of blinding of the investigators. The visible tape at the knee joint made a concealed data collection impossible. Furthermore, due to the painful progress of OA, the use of MVIC test is questionable. Patients are often unable to develop their full strength. Beside the application technique, this could indicate the lack of significant results in this study. The use of submaximal force test might be useful in future studies. In addition, difficult is the positioning of the sham-tape application. By the proximity to the knee joint, the influence of the tape is not excluded. However, a remote tape application from the knee joint makes the intervention not authentic.

\section{Conclusion}

The results of this study showed significant kinesio tape effects in the WOMAC subscales: pain, stiffness, and physical function compared with sham and control groups. This indicates that the use of kinesio tape over 3 consecutive days can improve selfreported symptoms of knee OA. Beneficial but no significant effects of the kinesio tape were also found for standing balance control while there were no changes in knee-extensor strength, walking speed, and knee ROM. The benefits of wearing an elastic tape demonstrated in this study applicable only for patients with the age of 50 years and older. As the clinical relevance of the observed effects is questionable, future studies should focus on kinesio tape in comparison with other conservative treatment measures.

\section{Acknowledgments}

The authors wish to express their sincere appreciation to Holger Gabriel for his insight and expertise who greatly assisted the research. This study was supported by BSN medical GmbH Hamburg, Germany. No declaration of interest was reported by the authors.

\section{References}

1. Johnson VL, Hunter DJ. The epidemiology of osteoarthritis. Best Pract Res Clin Rheumatol. 2014;28(1):5-15. PubMed ID: 24792942 doi:10.1016/j.berh.2014.01.004

2. Man GS, Mologhianu G. Osteoarthritis pathogenesis-a complex process that involves the entire joint. J Med Life. 2014;7(1):37-41. PubMed ID: 24653755 
3. Cross M, Smith E, Hoy D, et al. The global burden of hip and knee osteoarthritis: estimates from the global burden of disease 2010 study. Ann Rheum Dis. 2014;73(7):1323-1330. PubMed ID: 24553908 doi:10.1136/annrheumdis-2013-204763

4. Dieppe P. Developments in osteoarthritis. Rheumatology. 2011;50(2): 245-247. PubMed ID: 21242247 doi:10.1093/rheumatology/keq373

5. Goldring MB, Goldring SR. Articular cartilage and subchondral bone in the pathogenesis of osteoarthritis. Ann N Y Acad Sci. 2010;1192: 230-237. PubMed ID: 20392241 doi:10.1111/j.1749-6632.2009. 05240.x

6. Parreira PC, Costa LC, Hespanhol Junior LC, Lopes AD, Costa LO. Current evidence does not support the use of kinesio taping in clinical practice: a systematic review. J Physiother. 2014;60(1):31-39. PubMed ID: 24856938 doi:10.1016/j.jphys.2013.12.008

7. Morris D, Jones D, Ryan H, Ryan CG. The clinical effects of Kinesio ${ }^{\circledR}$ Tex taping: a systematic review. Physiother Theory Pract. 2013;29(4):259-270. PubMed ID: 23088702 doi:10.3109/09593985. 2012.731675

8. Williams S, Whatman C, Hume PA, Sheerin K. Kinesio taping in treatment and prevention of sports injuries: a meta-analysis of the evidence for its effectiveness. Sports Med. 2012;42(2):153-164. PubMed ID: 22124445 doi:10.2165/11594960-000000000-00000

9. González-Iglesias J, Fernández-de-las-Peñas C, Cleland J, Huijbregts P, Del Gutierrez-Vega M. Short-term effects of cervical kinesio taping on pain and cervical range of motion in patients with acute whiplash injury: a randomized clinical trial. J Orthop Sports Phys Ther. 2009;39(7):515-521. PubMed ID: 19574662 doi:10.2519/ jospt.2009.3072

10. Thelen MD, Dauber JA, Stoneman PD. The clinical efficacy of kinesio tape for shoulder pain: a randomized, double-blinded, clinical trial. J Orthop Sports Phys Ther. 2008;38(7):389-395. PubMed ID: 18591761 doi:10.2519/jospt.2008.2791

11. Halseth T, McChesney JW, DeBeliso M, Vaughn R, Lien J. The effects of kinesio ${ }^{\mathrm{TM}}$ taping on proprioception at the ankle. J Sports Sci Med. 2004;3(1):1-7. PubMed ID: 24497814

12. Chang HY, Chou KY, Lin JJ, Lin CF, Wang CH. Immediate effect of forearm kinesio taping on maximal grip strength and force sense in healthy collegiate athletes. Phys Ther Sport. 2010;11(4):122-127. PubMed ID: 21055705 doi:10.1016/j.ptsp.2010.06.007

13. Fayson SD, Needle AR, Kaminski TW. The effects of ankle kinesio taping on ankle stiffness and dynamic balance. Res Sports Med.2013; 21(3):204-216. PubMed ID: 23777376 doi:10.1080/15438627.2013. 792083

14. Hettle D, Linton L, Baker JS, Donoghue O. The effect of kinesiotaping on functional performance in chronic ankle instabilitypreliminary study. Clin Res Foot Ankle. 2013;1(1):1-5. doi:10. 4172/2329-910X.1000105

15. Nakajima MA, Baldridge $C$. The effect of kinesio ${ }^{\circledR}$ tape on vertical jump and dynamic postural control. Int J Sports Phys Ther. 2013;8(4): 393-406. PubMed ID: 24175126

16. Nunes GS, de Noronha M, Cunha HS, Ruschel C, Borges NG Jr. Effect of kinesio taping on jumping and balance in athletes: a crossover randomized controlled trial. J Strength Cond Res. 2013; 27(11):3183-3189. PubMed ID: 23439339 doi:10.1519/JSC. $0 \mathrm{~b} 013 \mathrm{e} 31828 \mathrm{a} 2 \mathrm{c} 17$

17. Shields CA, Needle AR, Rose WC, Swanik CB, Kaminski TW. Effect of elastic taping on postural control deficits in subjects with healthy ankles, copers, and individuals with functional ankle instability. Foot Ankle Int. 2013;34(10):1427-1435. PubMed ID: 23720530 doi:10.1177/1071100713491076

18. Shim JY, Lee HR, Lee DC. The use of elastic adhesive tape to promote lymphatic flow in the rabbit hind leg. Yonsei Med J. 2003;
44(6):1045-1052. PubMed ID: 14703615 doi:10.3349/ymj.2003.44. 6.1045

19. Białoszewski D, Woźniak W, Zarek S. Clinical efficacy of kinesiology taping in reducing edema of the lower limbs in patients treated with the ilizarov method-preliminary report. Ortop Traumatol Rehabil. 2008;11(1):46-54. PubMed ID: 19240683

20. Słupik A, Dwornik M, Białoszewski D, Zych E. Effect of kinesio taping on bioelectrical activity of vastus medialis muscle. Preliminary report. Ortop Traumatol Rehabil. 2006;9(6):644-651. PubMed ID: 18227756

21. Hsu YH, Chen WY, Lin HC, Wang WT, Shih YF. The effects of taping on scapular kinematics and muscle performance in baseball players with shoulder impingement syndrome. J Electromyogr Kinesiol. 2009;19(6):1092-1099. PubMed ID: 19147374 doi:10. 1016/j.jelekin.2008.11.003

22. Lin JJ, Hung CJ, Yang PL. The effects of scapular taping on electromyographic muscle activity and proprioception feedback in healthy shoulders. J Orthop Res. 2011;29(1):53-57. PubMed ID: 20607815 doi:10.1002/jor.21146

23. Huang CY, Hsieh TH, Lu SC, Su FC. Effect of the kinesio tape to muscle activity and vertical jump performance in healthy inactive people. Biomed Eng Online. 2011;10:70. PubMed ID: 21831321 doi:10.1186/1475-925X-10-70

24. Lee CR, Lee DY, Jeong HS, Lee MH. The effects of kinesio taping on VMO and VL EMG activities during stair ascent and descent by persons with patellofemoral pain: a preliminary study. $J$ Phys Ther Sci. 2012;24(2):153-156. doi:10.1589/jpts.24.153

25. Anandkumar S, Sudarshan S, Nagpal P. Efficacy of kinesio taping on isokinetic quadriceps torque in knee osteoarthritis: a double blinded randomized controlled study. Physiother Theory Pract. 2014;30(6): 375-383. PubMed ID: 24617598 doi:10.3109/09593985.2014. 896963

26. Cho HY, Kim EH, Kim J, Yoon YW. Kinesio taping improves pain, range of motion, and proprioception in older patients with knee osteoarthritis: a randomized controlled trial. Am J Phys Med Rehabil. 2015;94(3):192-200. PubMed ID: 25706053 doi:10.1097/PHM. 0000000000000148

27. Lawrence JS, Bremner JM, Bier F. Osteo-arthrosis: prevalence in the population and relationship between symptoms and x-ray changes. Ann Rheum Dis. 1966;25(1):1-24. PubMed ID: 5905334 doi:10. 1136/ard.25.1.1

28. Bellamy N, Buchanan WW, Goldsmith CH, Campbell J, Stitt LW. Validation study of WOMAC: a health status instrument for measuring clinically important patient relevant outcomes to antirheumatic drug therapy in patients with osteoarthritis of the hip or knee. J Rheumatol. 1988;15(12):1833-1840. PubMed ID: 3068365

29. Stucki G, Meier D, Stucki S, et al. Evaluation of a German version of the WOMAC (Western Ontario and McMaster universities) osteoarthritis index. Z Rheumatol. 1996;55(1):40-49. PubMed ID: 8868149

30. McConnell S, Kolopack P, Davis AM. The Western Ontario and McMaster Universities Osteoarthritis Index (WOMAC): a review of its utility and measurement properties. Arthritis Rheum. 2001;45(5): 453-461. PubMed ID: 11642645 doi:10.1002/1529-0131(200110) 45:5<453::AID-ART365>3.0.CO;2-W

31. Clark RC, Saxion CE, Cameron KL, Gerber JP. Associations between three clinical assessment tools for postural stability. $N$ Am J Sports Phys Ther. 2010;5(3):122-130. PubMed ID: 21589668

32. Bell DR, Guskiewicz KM, Clark MA, Padua DA. Systematic review of the balance error scoring system. Sports Health. 2011;3(3): 287-295. PubMed ID: 23016020 doi:10.1177/1941738111403122

33. Docherty CL, Valovich McLeod TCV, Shultz SJ. Postural control deficits in participants with functional ankle instability as measured by the balance error scoring system. Clin J Sport Med. 2006; 
16(3):203-208. PubMed ID: 16778539 doi:10.1097/00042752200605000-00003

34. Graham JE, Ostir GV, Fisher SR, Ottenbacher KJ. Assessing walking speed in clinical research: a systematic review. J Eval Clin Pract. 2008;14(4):552-562. PubMed ID: 18462283 doi:10.1111/j.13652753.2007.00917.x

35. Dirnberger J, Wiesinger HP, Stöggl T, Kösters A, Müller E. Absolute and relative strength-endurance of the knee flexor and extensor muscles: a reliability study using the IsoMed 2000-dynamometer. Sportverletz Sportschaden. 2012;26(3):142-147. PubMed ID: 23042045 doi:10.1055/s-0032-1329361

36. Jakobsen TL, Christensen M, Christensen SS, Olsen M, Bandholm T. Reliability of knee joint range of motion and circumference measurements after total knee arthroplasty: does tester experience matter? Physiother Res Int. 2010;15(3):126-134. PubMed ID: 20024893 doi: 10.1002/pri.450

37. Ryf C, Weymann A. The neutral zero method-a principle of measuring joint function. Injury. 1995;26:1-11. doi:10.1016/00201383(95)90116-7

38. Kase, K, Wallis, J, Kase, T. Clinical Therapeutic Applications of the Kinesio Taping Methods. 2nd ed. Tokyo, Japan: Ken Ikai Co. Ltd. 2003.

39. Escobar A, Quintana JM, Bilbao A, Arosteigui I, Lafuente I, Vidaurreta I. Responsiveness and clinically important differences for the WOMAC and SF-36 after total knee replacement. Osteoarthritis Cartilage. 2007;15(3):273-280. PubMed ID: 17052924 doi:10.1016/j.joca.2006.09.001

40. Bassett KT, Lingman SA, Ellis R. The use and treatment efficacy of kinaesthetic taping for musculoskeletal conditions: a systematic review. NZ J Physiother. 2010;38(2):56-62.

41. Riemann BL, Lephart SM. The sensorimotor system, part II: the role of proprioception in motor control and functional joint stability. J Athl Train. 2002;37(1):80-84. PubMed ID: 16558671

42. Jinks C, Jordan K, Croft P. Osteoarthritis as a public health problem: the impact of developing knee pain on physical function in adults living in the community: (KNEST 3). Rheumatology. 2007;46(5): 877-881. PubMed ID: 17308312 doi:10.1093/rheumatology/kem013

43. Angst F, Aeschlimann A, Steiner W, Stucki G. Responsiveness of the WOMAC osteoarthritis index as compared with the SF-36 in patients with osteoarthritis of the legs undergoing a comprehensive rehabilitation intervention. Ann Rheum Dis. 2001;60(9):834-840. PubMed ID: 11502609

44. Knoop J, van der Leeden M, Roorda LD, et al. Knee joint stabilization therapy in patients with osteoarthritis of the knee and knee instability: subgroup analyses in a randomized, controlled trial. J Rehabil Med. 2014;46(7):703-707. PubMed ID: 24910399 doi:10.2340/165019771809

45. Iverson GL, Kaarto ML, Koehle MS. Normative data for the balance error scoring system: implications for brain injury evaluations. Brain Inj. 2008;22(2):147-152. PubMed ID: 18240043 doi:10.1080/ 02699050701867407

46. Staehli S, Glatthorn JF, Casartelli N, Maffiuletti NA. Test-retest reliability of quadriceps muscle function outcomes in patients with knee osteoarthritis. J Electromyogr Kinesiol. 2010;20(6):1058-1065. PubMed ID: 20688529 doi:10.1016/j.jelekin.2010.07.006

47. Fu TC, Wong AM, Pei YC, Wu KP, Chou SW, Lin YC. Effect of Kinesio taping on muscle strength in athletes-a pilot study. J Sci Med Sport. 2008;11(2):198-201. PubMed ID: 17588814 doi:10. 1016/j.jsams.2007.02.011

48. Aytar A, Ozunlu N, Surenkok O, Baltaci G, Oztop P, Karatas M. Initial effects of kinesio $®$ taping in patients with patellofemoral pain syndrome: a randomized, double-blind study. Isokinet Exerc Sci. 2011;19(2):135-142.

49. Lins CA, Neto FL, Amorim AB, Macedo Lde B, Brasileiro JS. Kinesio Taping ${ }^{\circledR}$ does not alter neuromuscular performance of femoral quadriceps or lower limb function in healthy subjects: randomized, blind, controlled, clinical trial. Man Ther. 2013;18(1): 41-45. PubMed ID: 22796389 doi:10.1016/j.math.2012.06.009

50. Vercelli S, Sartorio F, Foti C, et al. Immediate effects of kinesiotaping on quadriceps muscle strength: a single-blind, placebo-controlled crossover trial. Clin J Sports Med. 2012;22(4):319-326. PubMed ID: 22450591 doi:10.1097/JSM.0b013e31824c835d

51. Wong OM, Cheung RT, Li RC. Isokinetic knee function in healthy subjects with and without kinesio taping. Phys Ther Sport. 2012; 13(4):255-258. PubMed ID: 23068902 doi:10.1016/j.ptsp.2012. 01.004

52. Guccione AA, Felson DT, Anderson JJ, et al. The effects of specific medical conditions on the functional limitations of elders in the Framingham Study. Am J Public Health. 1994;84(3):351-358. PubMed ID: 8129049 doi:10.2105/AJPH.84.3.351

53. Hurley MV, Scott DL, Rees J, Newham DJ. Sensorimotor changes and functional performance in patients with knee osteoarthritis. Ann Rheum Dis. 1997;56(11):641-648. PubMed ID: 9462165 doi:10. 1136/ard.56.11.641

54. van Dijk GM, Dekker J, Veenhof C, van den Ende CH. Course of functional status and pain in osteoarthritis of the hip or knee: a systematic review of the literature. Arthritis Care Res. 2006;55(5): 779-785. PubMed ID: 17013827 doi:10.1002/art.22244 